\title{
Ectima gangrenoso en un paciente pediátrico
}

\author{
Gangrenous ecthyma in a pediatric patient
}

Dante Alejandro Fuentes Mallozzi*

Paciente femenino de cinco meses de edad sin antecedentes de inmunodeficiencia y aparentemente sana. Fue llevada al hospital con múltiples lesiones en la piel de tipo máculas, pápulas, úlceras profundas, algunas en sacabocado y tejido ulcerativo con fondo necrótico en brazos, piernas y región lumbosacra (Figura 1). Desarrolló choque séptico y disfunción orgánica múltiple, que requirieron fármacos inotrópicos y vasoactivos, así como ventilación mecánica convencional y soporte vital para la vida. Los resultados de los exámenes de inmunoglobulinas, complemento y subpoblación de linfocitos fueron normales, por lo que se descartó inmunodeficiencia.

Se tomaron cultivos de sangre, líquido de ampolla, tejido necrótico, orina, heces y secreción endobronquial, y se reportó el aislamiento de Pseudomonas aeruginosa en los tres primeros. El reporte histopatológico de biopsia de

Figura 1: Lesión vesículo-ampollosa y úlceras profundas en sacabocado con fondo necrótico. piel reportó necrosis epidérmica con hemorragia dérmica masiva y aislados trombos de fibrina intravasculares. Tras quince días en cuidados intensivos pediátricos y nueve en preescolares, se egresó a su domicilio por mejoría (Figura 2).

El ectima gangrenoso es una infección poco frecuente de la piel, que se presenta en pacientes inmunodeficientes y/o con algún tipo de lesión primaria en piel. Generalmente es causada por Pseudomonas aeruginosa, pero también se han descrito otros gérmenes causantes como: Aeromonas hydrophila, Staphylococcus aureus, Streptococcus, Serratia marcescens, Aspergillus y Candida albicans. ${ }^{1}$

Las lesiones en piel se inician como máculo-pápulas eritematosas que rápidamente progresan a ampollas hemorrágicas, que fácilmente se rompen y dejan una costra purulenta, la cual, al desprenderse, muestra una úlcera profunda en sacabocado, con el borde indurado, elevado, eritematoso, violáceo y centro necrótico. ${ }^{2}$ Esto se debe a que los vasos capilares son invadidos a través de la adventicia por las bacterias que progresan hasta el

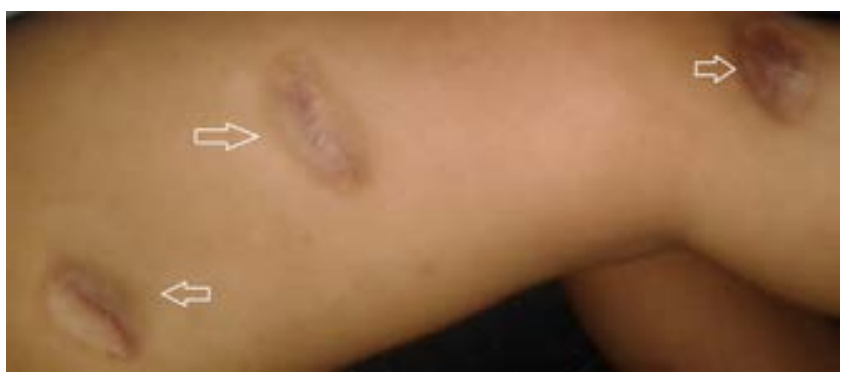

Figura 2: Cicatrices en sacabocado.

Correspondencia:

Dante Alejandro Fuentes Mallozzi

Correo electrónico: danteph@hotmail.com

Aceptado: 06-06-2019. \footnotetext{
de Salud. Ciudad Victoria, Tamaulipas.

* Pediatra intensivista.

Hospital Regional de Alta Especialidad "Bicentenario 2010", Secretaría
} 
lumen, ocasionando trombosis de los vasos y necrosis de la epidermis. Esta evolución del eritema inicial a necrosis toma de 12 a 18 horas, por eso en la forma clínica de la enfermedad podemos ver diferentes estadios evolutivos de ella. ${ }^{3}$ Esta entidad ocurre raramente en pacientes sanos, es muy agresiva cuando se presenta y de elevada morbimortalidad.

\section{REFERENCIAS}

1. Aguirre MCE, Flores SSG. Ectima gangrenoso como primera manifestación de choque séptico por Pseudomonas aeruginosa en un niño sano. An Med Asoc Med Hops ABC. 2016; 61 (4): 271-274.

2. Martínez PL, Cardona IL, Simons PSJ, Wilson CL. Ectima gangrenoso en un niño previamente sano. RIC. 2017; 96 (5): 950-958.

3. Rojas JP, López JM, Muñoz YA, González G. Ectima gangrenoso en pediatría. Infectio. 2013; 17 (1): 43-47. 